\title{
Hydroxyethyl starch 130/0.38-0.45 versus crystalloid or albumin in patients with sepsis: systematic review with meta-analysis and trial sequential analysis
}

\author{
(c) $\frac{(1)(8)}{\text { gy }}$ OPEN ACCESS
}

\author{
Nicolai Haase physician ${ }^{1}$, Anders Perner professor ${ }^{1}$, Louise Inkeri Hennings physician ${ }^{1}$, Martin \\ Siegemund professor ${ }^{2}$, Bo Lauridsen physician ${ }^{1}$, Mik Wetterslev medical student ${ }^{1}$, Jørn Wetterslev \\ chief physician $^{3}$
}

${ }^{1}$ Department of Intensive Care, Copenhagen University Hospital-Rigshospitalet, Blegdamsvej 9, DK-2100 Copenhagen, Denmark; ${ }^{2}$ Department of Anaesthesia, Intensive Care and Rescue Medicine, Baden State Hospital AG, Baden, Switzerland; ${ }^{3}$ Copenhagen Trial Unit, Centre for Clinical Intervention Research, Copenhagen University Hospital-Rigshospitalet, Blegdamsvej 3, DK-2200 Copenhagen, Denmark

\begin{abstract}
Objective To assess the effects of fluid therapy with hydroxyethyl starch 130/0.38-0.45 versus crystalloid or albumin on mortality, kidney injury, bleeding, and serious adverse events in patients with sepsis.

Design Systematic review with meta-analyses and trial sequential analyses of randomised clinical trials.

Data sources Cochrane Library, Medline, Embase, Biosis Previews, Science Citation Index Expanded, CINAHL, Current Controlled Trials, Clinicaltrials.gov, and Centerwatch to September 2012; hand search of reference lists and other systematic reviews; contact with authors and relevant pharmaceutical companies.

Study selection Eligible trials were randomised clinical trials comparing hydroxyethyl starch 130/0.38-0.45 with either crystalloid or human albumin in patients with sepsis. Published and unpublished trials were included irrespective of language and predefined outcomes.

Data extraction Two reviewers independently assessed studies for inclusion and extracted data on methods, interventions, outcomes, and risk of bias. Risk ratios and mean differences with $95 \%$ confidence intervals were estimated with fixed and random effects models.

Results Nine trials that randomised 3456 patients with sepsis were included. Overall, hydroxyethyl starch $130 / 0.38-0.45$ versus crystalloid or albumin did not affect the relative risk of death $(1.04,95 \%$ confidence interval 0.89 to $1.22,3414$ patients, eight trials), but in the predefined analysis of trials with low risk of bias the relative risk of death was 1.11 (1.00 to 1.23 , trial sequential analysis (TSA) adjusted $95 \%$ confidence interval 0.95 to $1.29,3016$ patients, four trials). In the hydroxyethyl starch group, renal replacement therapy was used more $(1.36,1.08$ to 1.72 , TSA adjusted 1.03 to $1.80,1311$ patients, five trials), and the relative
\end{abstract}

risk of acute kidney injury was 1.18 (0.99 to 1.40 , TSA adjusted 0.90 to $1.54,994$ patients, four trials). More patients in the hydroxyethyl starch group were transfused with red blood cells $(1.29,1.13$ to 1.48 , TSA adjusted 1.10 to $1.51,973$ patients, three trials), and more patients had serious adverse events $(1.30,1.02$ to 1.67 , TSA adjusted 0.93 to 1.83 , 1069 patients, four trials). The transfused volume of red blood cells did not differ between the groups (mean difference $65 \mathrm{~mL}, 95 \%$ confidence interval -20 to $149 \mathrm{~mL}$, three trials).

Conclusion In conventional meta-analyses including recent trial data, hydroxyethyl starch 130/0.38-0.45 versus crystalloid or albumin increased the use of renal replacement therapy and transfusion with red blood cells, and resulted in more serious adverse events in patients with sepsis. It seems unlikely that hydroxyethyl starch $130 / 0.38-0.45$ provides overall clinical benefit for patients with sepsis.

\section{Introduction}

Colloids are used more often for resuscitation in the intensive care unit than crystalloids. The choice of colloid varies noticeably between countries, but worldwide hydroxyethyl starch is most commonly used and thus more used than, for example, human albumin and gelatin. ${ }^{1}$ The use of hydroxyethyl starch is controversial as the former higher molecular weight hydroxyethyl starch 200/0.5-0.6 caused acute kidney injury in two randomised clinical trials of patients with sepsis. ${ }^{23}$ The newer starches with molecular weights of $130 \mathrm{kDa}$ and substitution ratios ranging from 0.38 to 0.45 have been claimed to be safer, but the data to support this are insufficient. ${ }^{4}$ Owing to the lack of data on hydroxyethyl starch 130/0.38-0.45, previous systematic reviews have been inconclusive about the 
benefits and harms of this colloid compared with other fluids. ${ }^{4-8}$ The recent publication of three large trials comparing hydroxyethyl starch 130/0.38-0.45 with crystalloids in patients with sepsis calls for an updated systematic review to inform on the benefits and harms of this colloid in patients with sepsis, which is highly needed as fluid alternatives are available. ${ }^{9-11}$

We assessed the effects of hydroxyethyl starch 130/0.38-0.45 versus crystalloids or human albumin on all cause mortality, kidney injury, bleeding, and serious adverse events in patients with sepsis.

\section{Methods}

This systematic review is based on the methodology recommended by the Cochrane Collaboration. ${ }^{12}$ The protocol was published in the PROSPERO register (www.crd.york.ac. uk/PROSPERO) before the literature search.

\section{Eligibility criteria}

Potentially eligible trials had to be prospective and randomised, include patients with sepsis, have one intervention group that received hydroxyethyl starch 130 with substitution ratios between 0.38 and 0.45 in any concentration and in any carrier solution, and have at least one other intervention group that received either crystalloid or human albumin.

We included trials irrespective of language, publication status, patient's age, indication for fluid therapy, and predefined outcomes. If the patients with sepsis constituted a subgroup of the trial population, we included the trial only if the randomisation was stratified for the presence of sepsis or if the population with sepsis was larger than 500 participants. We also included quasirandomised and observational studies with more than 500 patients receiving hydroxyethyl starch 130/0.38-0.45, but evaluated these for serious adverse events only. Exclusion criteria were studies in animals, patients without sepsis, hydroxyethyl starch products of other molecular weights or substitution ratios, crossover studies, and studies comparing hydroxyethyl starch with other synthetic colloid solutions.

\section{Search strategy}

We searched the Cochrane central register of controlled trials, Medline, Embase, Biosis Previews, Science Citation Index Expanded, and Cumulative Index to Nursing and Allied Health Literature. As hydroxyethyl starch 130/0.38-0.45 was introduced on the market in 1999 we limited the search to references from 1995 or later. We also hand searched the reference lists of included trials and other systematic reviews of fluid therapy for further trials.

Unpublished trials were sought through trial registries (www. controlled-trials.com, www.clinicaltrials.gov, and www. centerwatch.com), and we contacted relevant pharmaceutical companies for unpublished data. The electronic literature search was last updated 10 September 2012. See the supplementary file for details of the search, including the search string.

\section{Study selection}

Two authors (NH, LIH, BL, or MW) independently reviewed all titles and abstracts identified in the literature search and excluded trials that were obviously not relevant. The remaining trials were evaluated in full text. Disagreements were resolved with JW.

\section{Data extraction}

Two authors (NH, LIH) independently extracted information from each included trial by using a pre-made data extraction form. The extracted information included trial characteristics (single or multicentre and country), characteristics of the trial participants (age, sex, and disease severity), criteria for inclusion and exclusion, type of intervention (indication, dosing, duration, and comparator fluid), and outcomes.

The predefined primary outcomes of this review were overall mortality and number of patients still receiving renal replacement therapy at the maximum length of follow-up. The predefined secondary outcomes were the number of patients receiving renal replacement therapy at any time during the follow-up period, number of patients having acute kidney injury, number of patients receiving red blood cell transfusion, total volume of red blood cells transfused, number of patients having a bleeding episode, estimated blood loss, and number of patients having one or more serious adverse events. We contacted the corresponding authors for data on outcomes that were not reported in their publications.

Translators extracted data from all relevant non-English articles.

\section{Risk of bias assessment}

To determine the validity of the included trials, we assessed the risk of bias as advised by the Cochrane Collaboration, ${ }^{12}$ including the domains of random sequence generation, allocation concealment, blinding, incomplete outcome data, selective outcome reporting, baseline imbalance, bias due to vested financial interest, and academic bias. If one or more domains were judged as being high or unclear, we classified the trial as having a high risk of bias. Since the need for fluids is difficult to assess objectively, the choice to give fluid instead of vasopressors or inotropes may depend on the expected potency of the fluid. Thus, unblinding may lead to systematic differences in interventions or cointerventions between the intervention groups, so we classified all unblinded trials as being at high risk of bias for all outcomes including mortality unless study fluids were given in fixed doses.

\section{Statistical analysis}

Review Manager 5.1.6 was used for statistical analyses, and we used the TSA program version 0.9 beta (www.ctu.dk/tsa) for trial sequential analyses. For each included trial we calculated the relative risks (95\% confidence intervals) for dichotomous outcomes and risk difference (95\% confidence intervals) for continuous outcomes, and we pooled these measures in meta-analyses.

Heterogeneity among trials was quantified with inconsistency factor $\left(\mathrm{I}^{2}\right)$ statistics. If the $\mathrm{I}^{2}$ statistic was 0 , we reported the results from a fixed effect model. If the $\mathrm{I}^{2}$ statistic was greater than 0 , we reported the results from both random effects and fixed effects models.

Sensitivity analyses included application of continuity correction in trials of zero events ${ }^{13}$ and exclusion of the smallest trial, the largest trial, and trials financed by industry.

We did a predefined subgroup analysis with stratification of trials according to risk of bias. To further explore possible reasons for a high or moderate statistical heterogeneity we did an explorative post hoc subgroup analysis stratifying trials according to length of follow-up.

Some authors have suggested that conventional meta-analysis should not be trusted without further evaluation, as cumulative meta-analyses of trials are at risk of producing random errors 
because of sparse data and repetitive testing of accumulating data. ${ }^{14}{ }^{15} \mathrm{We}$ therefore challenged the meta-analyses with the application of trial sequential analysis - a sensitivity analysis that widens the confidence intervals in case the data are too sparse to draw firm conclusions. Trial sequential analysis is similar to interim analysis in a single trial where the monitoring boundaries are used to decide whether the $P$ value is sufficiently small to show the anticipated effect and whether the trial should be terminated early. In the same manner, trial sequential monitoring boundaries can be applied to meta-analyses. ${ }^{14-17}$

Trial sequential analysis depends on the quantification of the required information size (the meta-analysis sample size). We calculated a diversity, $\mathrm{D}^{2}$, adjusted required information size since the heterogeneity adjustment with $\mathrm{I}^{2}$ underestimate the required information size. ${ }^{18} \mathrm{We}$ did the trial sequential analysis with the intention to maintain an overall $5 \%$ risk of a type I error and a power of $80 \%$. For the calculation of the required information size we anticipated an intervention effect of a $20 \%$ relative risk increase. For renal replacement therapy, bleedings, and serious adverse events we used an anticipated effect of 35\%, since we expected a much lower event proportion for these outcomes. For mortality, we observed only an $11 \%$ relative risk increase in trials with low risk of bias and used this effect instead in the trial sequential analysis of mortality. We provide the $95 \%$ confidence intervals adjusted for sparse data and repetitive testing, which we describe as the trial sequential analysis adjusted $95 \%$ confidence intervals.

\section{Results}

Figure $1 \Downarrow$ summarises the results of the search. The main reasons for exclusion of randomised trials were that the patients did not have sepsis and the trials evaluated a hydroxyethyl starch solution other than hydroxyethyl starch 130/0.38-0.45 (see supplementary table). ${ }^{19-50}$ No language restrictions were applied; one paper was in Spanish, one in Japanese, four in Russian, and four in Chinese. Overall nine trials met the inclusion criteria..$^{9-11}{ }^{51-56}$ One trial was still unpublished..$^{51}$ The authors of six trials were successfully contacted ${ }^{9-11515354}$ and data were obtained for eight. ${ }^{9-115153-56}$ A Chinese researcher extracted data from two trials published in Chinese. ${ }^{55}{ }^{56}$ All other trials were published in English. No observational study was identified with more than 500 patients with sepsis receiving hydroxyethyl starch 130/0.38-0.45 to evaluate for adverse events.

\section{Characteristics of trials}

The four largest trials were blinded and had long term ( $>28$ days) follow-up. ${ }^{9-1151}$ The remaining trials were either unblinded, had unclear methodology, or had shorter follow-up times $(\leq 28$ days). Table $1 \Downarrow$ shows the characteristics of the included trials, and table $2 \Downarrow$ the observation period for each outcome.

\section{Participants}

The included trials enrolled 3456 adults with sepsis on an intensive care unit. One trial included a broad spectrum of patients on the intensive care unit, but in this review only the subgroup of patients with sepsis were included. ${ }^{10}$ All but two trials included patients with both sepsis and organ failure (severe sepsis). ${ }^{1051}$ The definitions of organ failure varied slightly between trials, but in most included various clinical signs of hypoperfusion as, for example, oliguria, hypotension, and increased lactate levels. Only one trial specifically stated that all patients had septic shock. ${ }^{55}$

\section{Interventions}

The type of hydroxyethyl starch studied was $6 \%$ Voluven (hydroxyethyl starch 130/0.4 (range 0.38-0.45) in saline, Fresenius Kabi, Bad Homburg, Germany) in six trials, ${ }^{10} 1151-54$ 6\% Tetraspan (hydroxyethyl starch 130/0.42 (range 0.40-0.44) in Ringer's acetate, B Braun Melsungen, Melsungen, Germany) in one trial, ${ }^{9}$ and $6 \%$ hydroxyethyl starch $130 / 0.4$ without a statement of the brand name in two trials. ${ }^{55}{ }^{56}$ Two trials compared starch with human albumin $20 \%,{ }^{52}{ }^{53}$ whereas the remaining trials used crystalloid as comparator. In one study two groups received hydroxyethyl starch 130/0.4 in isotonic saline or hypertonic saline. ${ }^{56}$ These groups were pooled and compared with the third group receiving Ringer's lactate. Trial fluid was used for resuscitation in eight trials ${ }^{9-11} 51$ 52 54-56 and given as fixed doses in one trial. ${ }^{53}$ The duration of the intervention varied from 24 hours to the entire stay on the intensive care unit to a maximum of 90 days. Cumulative doses of hydroxyethyl starch ranged from 2.1 litres to 6.4 litres with no obvious relation between duration of intervention and total dose.

\section{Bias risk assessment}

The risk of bias could be fully judged in six trials. ${ }^{9-11515354}$ Four of these were judged to be of low risk of bias in all domains, ${ }^{9}{ }^{10} 5153$ the fifth was sponsored by industry and had potential academic bias, ${ }^{11}$ and the sixth had a high risk of bias owing to lack of blinding. ${ }^{54}$

In the remaining three trials at least one domain was judged to be unclear, but all of these trials were judged to be of high risk of bias in other domains (table $3 \Downarrow$, also see the supplementary file).

\section{Clinical outcomes}

\section{All cause mortality}

Mortality data were obtained from eight trials including 3414 patients. ${ }^{9-115153-56}$ The observation period in four of these trials (3156 patients) was longer than 28 days (table 2). ${ }^{9-1151}$ The meta-analysis of all eight trials showed no significant difference in mortality in patients treated with hydroxyethyl starch 130/0.38-0.45 compared with crystalloid or albumin (random effects: relative risk $1.04,95 \%$ confidence interval 0.89 to 1.22 ; $\mathrm{P}=0.64$; fixed effect: $1.08,0.98$ to $1.19 ; \mathrm{P}=0.13 ; \mathrm{I}^{2}=37 \%$; fig $2 \Downarrow)$. The trial sequential analysis adjusted $95 \%$ confidence interval was 0.70 to 1.54 (see supplementary file). The predefined analysis of trials with low risk of bias showed a relative risk of 1.11 ( 1.00 to $1.23 ; \mathrm{P}=0.05 ; \mathrm{I}^{2}=0 \%$ ), but the test for subgroup difference between trials with low versus high risk of bias was not significant ( $\mathrm{P}=0.13$, fig 2 ). Trial sequential analysis of trials with low risk of bias showed that 3016 of the required information size of 6237 patients was accrued. The cumulative $\mathrm{z}$ curve touched the conventional boundary for harm but did not cross the trial sequential monitoring boundary for harm (trial sequential analysis adjusted $95 \%$ confidence interval of trials with low risk of bias 0.95 to 1.29 ) (fig $3 \Downarrow$ ). However, the $\mathrm{z}$ curve will need to pass through the futility area to reach the area of benefit, leaving little chance that hydroxyethyl starch will turn out to reduce the relative risk of death with $11 \%$ if further trials are conducted in patients with sepsis.

The post hoc subgroup analysis according to time of follow-up showed a significant increase in all cause mortality in trials with follow-up for more than 28 days (relative risk 1.11, 95\% confidence interval 1.01 to $1.22 ; \mathrm{P}=0.04 ; \mathrm{I}^{2}=0 \%$ ) versus a non-significant decrease in all cause mortality in trials with 
follow-up for 28 days or less $(0.63,0.35$ to $1.15 ; \mathrm{P}=0.13)$. The test for subgroup differences was not significant at the $5 \%$ level ( $\mathrm{P}=0.07$, see supplementary file). The trial sequential analysis adjusted $95 \%$ confidence intervals of trials with follow-up for more than 28 days was 0.95 to 1.29 (see supplementary file).

\section{Renal replacement therapy at end of follow-up}

Five trials had data on renal replacement therapy, with observation periods ranging from 24 hours to one year. ${ }^{911515354}$ The Scandinavian Starch for Severe Sepsis/Septic Shock (6S) trial reported that two patients-one in each intervention group-were still being treated with renal replacement therapy at the end of follow-up. ${ }^{9}$ In Basel Starch Evaluation in Sepsis $(\mathrm{BaSES})^{51}$ no patient required renal replacement therapy after one year, and in the trial by Guidet et al (CRYSTMAS) ${ }^{11}$ one patient in the hydroxyethyl starch group was treated with renal replacement therapy for more than 28 days, but it was unclear whether this lasted until end of follow-up. These data did not undergo meta-analysis.

\section{Renal replacement therapy at anytime during follow-up}

The same five trials had data on the number of patients treated with renal replacement therapy at anytime during follow-up. One trial had zero events in three days. ${ }^{53}$ The pooled analysis showed that patients receiving hydroxyethyl starch 130/0.38-0.45 had a significantly increased risk of receiving renal replacement therapy (relative risk $1.36,95 \%$ confidence interval 1.08 to $1.72 ; \mathrm{P}=0.009 ; \mathrm{I}^{2}=0 \%$; fig $4 \Downarrow$ ). Application of an empirical continuity correction of 0.01 in the no event trial did not change the result. Trial sequential analysis showed that 1311 of the required information size of 1654 patients was accrued, but the cumulative $\mathrm{z}$ curve crossed the trial sequential monitoring boundary for harm providing firm evidence of increased use of renal replacement therapy in patients treated with hydroxyethyl starch compared with crystalloid or albumin (trial sequential analysis adjusted $95 \%$ confidence interval 1.03 to 1.80 ) (fig $5 \Downarrow$ ).

\section{Acute kidney injury}

Acute kidney injury was defined as a twofold increase of serum creatinine levels during the observation period, as this was consistently reported in the four trials with data on kidney function. ${ }^{9115354}$ The observation periods ranged from 24 hours to the entire stay on the intensive care unit. One trial had no events,$^{53}$ and the pooled analysis of the remaining three trials showed a non-significant increase in the risk of acute kidney injury in the hydroxyethyl starch group (relative risk 1.18, 95\% confidence interval 0.99 to $1.40 ; \mathrm{P}=0.07 ; \mathrm{I}^{2}=0 \%$ ) (see supplementary file). Application of an empirical continuity correction of 0.01 in the no event trial did not change the result. The trial sequential analysis adjusted $95 \%$ confidence interval was 0.90 to 1.54 (see supplementary file).

\section{Transfusions with red blood cells, bleeding, and blood loss}

Three trials provided data on transfusions, with observation periods ranging from 24 hours to the entire stay on the intensive care unit. ${ }^{91154}$ The risk of being transfused with red blood cells was significantly higher in the hydroxyethyl starch group (1.29, $95 \%$ confidence interval 1.13 to $1.48 ; \mathrm{P}<0.001 ; \mathrm{I}^{2}=0 \%$ ) (see supplementary file). The trial sequential analysis adjusted $95 \%$ confidence interval was 1.10 to 1.51 , providing firm evidence for an increased risk of transfusion with red blood cells if treated with hydroxyethyl starch 130/0.38-0.45 (see supplementary file).

The mean volume of red blood cells did not differ between the groups (mean difference $65 \mathrm{~mL}, 95 \%$ confidence interval -20 to $149 \mathrm{~mL} ; \mathrm{P}=0.13 ; \mathrm{I}^{2}=0 \%$ ) (see supplementary file).

The number of patients having at least one bleeding episode (relative risk $1.34,95 \%$ confidence interval 0.81 to $2.21 ; \mathrm{P}=0.26$; $\mathrm{I}^{2}=38 \%$ ) and blood loss (mean difference $26 \mathrm{~mL},-89$ to 140 $\mathrm{mL} ; \mathrm{P}=0.66 ; \mathrm{I}^{2}=0 \%$ ) were reported in two trials (see supplementary file). ${ }^{911}$

\section{Serious adverse events}

Four trials reported serious adverse events, two of which registered these during the entire stay on the intensive care unit. ${ }^{9115354}$ In the $6 \mathrm{~S}$ trial serious adverse events were restricted to severe bleeding and severe allergic reactions, ${ }^{9}$ whereas CRYSTMAS used broad criteria. ${ }^{11}$ The last two trials did not specify the definition of serious adverse events, and one of them had zero events in 24 hours follow-up. ${ }^{54}$ According to the good clinical practice guidelines by the International Conference on Harmonisation, death should count as a serious adverse event in the analysis, ${ }^{57}$ but we were unable to get the composite endpoint of either death or serious adverse events from more than one trial. ${ }^{9}$

The pooled analysis of the three trials showed a significantly increased risk of serious adverse events with hydroxyethyl starch 130/0.38-0.45 (relative risk $1.30,95 \%$ confidence interval 1.02 to $1.67 ; \mathrm{P}=0.03 ; \mathrm{I}^{2}=0 \%$ ) (see supplementary file). The application of a continuity correction to the zero event trial neither changed the estimate nor the confidence interval. The trial sequential analysis adjusted $95 \%$ confidence interval was 0.93 to 1.83 (see supplementary file).

\section{Discussion}

The main finding of this systematic review was that patients assigned to hydroxyethyl starch 130/0.38-0.45 had in conventional meta-analysis a statistically significant increased risk of getting renal replacement therapy, transfusion with red blood cells, and serious adverse events. The recent large, well designed trials showed consistent results with no statistical heterogeneity and the findings are likely to be confirmed when further data of the patients with sepsis in the Crystalloid versus Hydroxyethyl Starch (CHEST) trial ${ }^{10}$ become available, since the hydroxyethyl starch group in this trial had more use of renal replacement therapy and transfusion with red blood cells and more serious adverse events.

The pooled analysis of mortality showed neither benefit nor harm, but trials with a low risk of bias suggested an excess mortality of $11 \%$. In addition, our post hoc analysis of trials with follow-up for more than 28 days showed increased mortality. Thus the pooled analysis of mortality may be influenced by trials of poor quality and too short follow-up, making interpretation difficult.

The sensitivity analysis with trial sequential analysis widened the confidence intervals of the conventional meta-analyses when data were too sparse to draw firm conclusions. With this strict approach the increased risk of renal replacement therapy and transfusion with red blood cells remained statistically significant. For mortality in trials with low risk of bias and long term follow-up, trial sequential analysis indicated a lack of statistical significance for increased mortality, but also that it is unlikely that hydroxyethyl starch will result in a relative mortality 
reduction of $11 \%$ if further trials are conducted in patients with sepsis.

Our results are consistent with the fact that a high fraction of hydroxyethyl starch 130/0.38-0.45 is deposited in the tissues where it cannot be metabolised ${ }^{58}$ and may act as a foreign body with long term toxic effects, which have been described in the kidney, liver, and bone marrow. ${ }^{59-61}$ In addition, the use of renal replacement therapy has repeatedly been associated with death. ${ }^{62}{ }^{63}$ Our findings are in alignment with the results of two sepsis trials of hydroxyethyl starch 200/0.5-0.6 on renal impairment and late adverse effects. ${ }^{23}$ Thus the adverse effects of hydroxyethyl starch may be a class effect independent of molecular weight and substitution ratio.

Some hypothesise that bad outcome in patients treated with hydroxyethyl starch is due to inappropriate dosing, including the lack of predefined triggers and goals for fluid resuscitation. No data currently support this belief, as there was no suggestion of an overall favourable outcome in any trial with adequate bias control and follow-up - not even in the trial designed by one of the manufacturers of hydroxyethyl starch. ${ }^{11}$

\section{Strengths and limitations of the review}

The compliance with the recommendations of the Cochrane Collaboration is a major strength of our systematic review. This included a prepublished protocol, an up to date extensive literature search with no language restrictions, independent screening of all references by two authors, inclusion of trials irrespective of publication and language status and reported outcomes, independent data extraction by two authors, bias risk assessment, and contact with the corresponding authors of the included trials for additional information. In addition, we reduced the risk of random error in the meta-analyses with the application of trial sequential analysis using predefined variables to increase the robustness of this analysis.

We excluded trials comparing hydroxyethyl starch with other synthetic colloids that may possess the same harmful effects and thereby mask any adverse effects of hydroxyethyl starch. ${ }^{64}$ To get a clinical applicable result, we restricted the review to hydroxyethyl starch 130/0.38-0.45 as clinicians almost exclusively use these starches. Including all types of hydroxyethyl starch in the analysis would probably have resulted in a stronger group difference instead.

The post hoc subgroup analysis of mortality in trials according to length of follow-up might have resulted in spurious findings. In general, however, some adverse effects undoubtedly develop slowly, and if the observation period is too short, such events may not be captured. In the largest trials of hydroxyethyl starch in sepsis the relative risk of death increased from day 28 to day 90 , indicating that the observation period for mortality should be longer than 28 days, and this was the rationale for our subgroup analysis. ${ }^{2} 910$

We chose to include trials with either crystalloid or albumin solutions as comparators as no adverse effects were seen with albumin versus saline in patients with severe sepsis in a large intensive care unit trial. ${ }^{65}$ However, most of the included trials compared hydroxyethyl starch with a crystalloid, and this may prevent us from drawing firm conclusions on the effects of albumin. Neither can this review tell whether patients other than those with sepsis may experience adverse effects from hydroxyethyl starch, but the CHEST trial found increased serious adverse events and use of renal replacement therapy with hydroxyethyl starch in a broad population of intensive care unit patients, suggesting adverse effects beyond those seen in sepsis.
Additional limitations of this review are due to bias of the included trials, inadequate follow-up, and trials not reporting all the outcome measures. The definitions of serious adverse events were heterogeneous, so the group difference should be interpreted with caution. The RIFLE (Risk of renal dysfunction, Injury to the kidney, Failure of kidney function, Loss of kidney function and End-stage renal disease) ${ }^{66}$ and AKIN (Acute Kidney Injury Network $)^{67}$ classifications may be better measures for acute kidney injury, but we used renal replacement therapy and doubling of creatinine levels instead as these more simple outcomes were more often reported.

\section{Relation to other reviews and implication for future research}

Several well conducted systematic reviews have been published on hydroxyethyl starch $130 / 0.38-0.45^{48}$ and on hydroxyethyl starch and fluid therapy in general.$^{5-7}$ Owing to the previous lack of data on hydroxyethyl starch 130/0.38-0.45, these reviews have been inconclusive about the benefit and harm of hydroxyethyl starch 130/0.38-0.45 compared with other fluids. In comparison, this review contains data from new large trials and applies trial sequential analysis on the results.

Hydroxyethyl starch 130/0.38-0.45 is often used in the surgical setting and may continue despite the raised safety issues in patients with sepsis. If use does continue, then well powered surgical trials are urgently needed to ensure the safety of patients.

\section{Conclusion}

In conventional meta-analyses including recent trial data, hydroxyethyl starch 130/0.38-0.45 versus crystalloid or albumin in patients with sepsis was associated with an increased use of renal replacement therapy and transfusion with red blood cells and more serious adverse events. The pooled analysis of mortality showed no group difference, but this analysis may be influenced by trials of low quality. After trial sequential analysis adjustment for sparse data and multiple updating in cumulative meta-analysis it seems unlikely that hydroxyethyl starch provides overall clinical benefit for patients with sepsis.

We thank Sarah Klingenberg, search coordinator for the Cochrane Hepato-Biliary Group, for performing the literature search; Xia Yun for evaluating references in Chinese and extracting data from two Chinese articles included in the review; Dimitrenka Nikolova, Copenhagen Trial Unit, for evaluating four papers in Russian; Naoya Sakamoto for evaluating one paper in Japanese; and Arnaldo Dubin, Petr Svoboda, and Martin Westphal for providing data for this systematic review. The trial protocol was registered through PROSPERO (registration No CRD42011001762).

Contributors: NH developed the protocol, was responsible for the searches, selected trials, extracted data, assessed the risk of bias of trials, did the data analysis, and developed the final review. AP developed the protocol, analysed data, and developed the final review. $\mathrm{LIH}$ developed the protocol, selected trials, extracted data, assessed the risk of bias of trials, and developed the final review. MS extracted data, assessed the risk of bias of trials, and developed the final review. $\mathrm{BL}$ and MW developed the protocol, selected trials, and developed the final review. JW developed the initial idea for the review, developed the protocol, selected trials, advised on statistical methods, analysed data, and developed the final review. All authors read and approved the final manuscript. $\mathrm{NH}$ and JW are the guarantors.

Competing interests: All authors have completed the ICMJE uniform disclosure form at www.icmje.org/coi_disclosure.pdf (available on request from the corresponding author) and declare: AP was principal 


\section{What is already known on this topic}

Hydroxyethyl starches (HES) with molecular weights of $130 \mathrm{kDa}$ and substitution ratios ranging from 0.38 to 0.45 are the most commonly used colloids wordwide, but their safety and efficacy have not been established in patients with sepsis

Owing to lack of data, previous systematic reviews on HES 130/0.38-0.45 and on HES in general have been inconclusive about the benefits and harms of HES compared with other fluids

\section{What this study adds}

This systematic review includes the results of four recent randomised clinical trials of HES 130/0.38-0.45 comprising more than 3000 patients with sepsis

The pooled analysis of trials showed that treatment with HES increased the risk of having renal replacement therapy, red blood cell transfusion, and severe adverse reactions

It seems unlikely therefore that HES provides overall clinical benefit for patients with sepsis

investigator for the Scandinavian Starch for Severe Sepsis/Septic Shock (6S) trial and $\mathrm{NH}$ and $\mathrm{JW}$ were members of the steering committee. The $6 \mathrm{~S}$ trial was funded by the Danish Research Council, the Rigshospitalet Research Council, and the Scandinavian Society of Anaesthesiology and Intensive Care Medicine (the ACTA foundation). B Braun Melsungen delivered trial fluid to all sites free of charge. Neither the funders nor B Braun Melsungen had an influence on the protocol, trial conduct, data analyses, or reporting of the $6 \mathrm{~S}$ trial. AP is head of research in his intensive care unit, which receives research funds from Fresenius Kabi and BioPorto. B Braun Melsungen has covered his travel expenses for presenting $6 \mathrm{~S}$ data at the German Anaesthetic Congress 2012. MS was principal investigator for the Basel starch evaluation in sepsis (BaSES) trial. The BaSES trial was funded by the Department of Anaesthesia and Intensive Care of the University Hospital Basel. Fresenius Kabi delivered study fluids for free and paid for the packaging and blinding process. A signed contract between Fresenius Kabi and MS stated that MS was free to publish all data without influence from Fresenius Kabi. Fresenius Kabi covered travel expenses for MS's participation in meetings about fluid resuscitation.

Ethical approval: Not required.

Data sharing: No additional data available.

Finfer S, Liu B, Taylor C, Bellomo R, Billot L, Cook D, et al. Resuscitation fluid use in critically ill adults: an international cross-sectional study in 391 intensive care units. Crit Care 2010;14:R185.

2 Brunkhorst FM, Engel C, Bloos F, Meier-Hellmann A, Ragaller M, Weiler N, et al. Intensive insulin therapy and pentastarch resuscitation in severe sepsis. $N$ Engl $\mathrm{J} \mathrm{Med}$ 2008;358:125-39.

3 Schortgen F, Lacherade JC, Bruneel F, Cattaneo I, Hemery F, Lemaire F, et al. Effects of hydroxyethylstarch and gelatin on renal function in severe sepsis: a multicentre randomised study. Lancet 2001;357:911-6.

4 Hartog CS, Kohl M, Reinhart K. A systematic review of third-generation hydroxyethyl starch (HES 130/0.4) in resuscitation: safety not adequately addressed. Anesth Analg 2011;112:635-45.

5 Dart AB, Mutter TC, Ruth CA, Taback SP. Hydroxyethyl starch (HES) versus other fluid therapies: effects on kidney function. Cochrane Database Syst Rev 2010;(1):CD007594.

6 Perel P, Roberts I. Colloids versus crystalloids for fluid resuscitation in critically ill patients. Cochrane Database Syst Rev 2011;(6):CD000567.

7 Bunn F, Trivedi D, Ashraf S. Colloid solutions for fluid resuscitation. Cochrane Database Syst Rev 2012;(6):CD001319.

8 Gattas DJ, Dan A, Myburgh J, Billot L, Lo S, Finfer S. Fluid resuscitation with 6\% hydroxyethyl starch (130/0.4) in acutely ill patients: an updated systematic review and meta-analysis. Anesth Analg 2012;114:159-69.

9 Perner A, Haase N, Guttormsen AB, Tenhunen J, Klemenzson G, Åneman A, et al. Hydroxyethyl starch 130/0.42 versus Ringer's acetate in severe sepsis. N Engl J Med 2012;367:124-34

10 Myburgh JA, Finfer S, Bellomo R, Billot L, Cass A, Gattas D, et al. Hydroxyethyl starch or saline for fluid resuscitation in intensive care. N Engl J Med 2012;367:1901-11.

11 Guidet B, Martinet O, Boulain T, Philippart F, Poussel JF, Maizel J, et al. Assessment of hemodynamic efficacy and safety of $6 \%$ hydroxyethylstarch $130 / 0.4 \mathrm{vs} .0 .9 \% \mathrm{NaCl}$ fluid replacement in patients with severe sepsis: The CRYSTMAS study. Crit Care 2012;16:R94.

12 Higgins JPT, Green S. Cochrane handbook for systematic reviews of interventions, version 5.1.0 [updated March 2011]. The Cochrane Collaboration 2011. Available from www. cochrane-handbook.org; 2012

13 Sweeting MJ, Sutton AJ, Lambert PC. What to add to nothing? Use and avoidance of continuity corrections in meta-analysis of sparse data. Stat Med 2004;23:1351-75.

14 Wetterslev J, Thorlund K, Brok J, Gluud C. Trial sequential analysis may establish when firm evidence is reached in cumulative meta-analysis. J Clin Epidemiol 2008;61:64-75.

15 Higgins JP, Whitehead A, Simmonds M. Sequential methods for random-effects meta-analysis. Stat Med 2011;30:903-21.

16 Thorlund K, Imberger G, Walsh M, Chu R, Gluud C, Wetterslev J, et al. The number of patients and events required to limit the risk of overestimation of intervention effects in meta-analysis-a simulation study. PLoS One 2011;6:e25491.
17 Brok J, Thorlund K, Gluud C, Wetterslev J. Trial sequential analysis reveals insufficient information size and potentially false positive results in many meta-analyses. $J$ Clin Epidemiol 2008;61:763-9.

18 Wetterslev J, Thorlund K, Brok J, Gluud C. Estimating required information size by quantifying diversity in random-effects model meta-analyses. BMC Med Res Methodol 2009;9:86.

19 Ando Y, Terao Y, Fukusaki M, Yamashita K, Takada M, Tanabe T, et al. Influence of low-molecular-weight hydroxyethyl starch on microvascular permeability in patients undergoing abdominal surgery: comparison with crystalloid. J Anesth 2008;22:391-6.

20 Wills BA, Nguyen MD, Ha TL, Dong TH, Tran TN, Le TT, et al. Comparison of three fluid solutions for resuscitation in dengue shock syndrome. N Engl J Med 2005;353:877-89.

21 Asfar P, Kerkeni N, Labadie F, Gouëllo JP, Brenet O, Alquier P. Assessment of hemodynamic and gastric mucosal acidosis with modified fluid versus $6 \%$ hydroxyethyl starch: a prospective, randomized study. Intens Care Med 2000;26:1282-7.

22 Boldt J, Heesen M, Welters I, Padberg W, Martin K, Hempelmann G. Does the type of volume therapy influence endothelial-related coagulation in the critically ill? Brit J Anaesth 1995;75:740-6.

23 Boldt J, Muller M, Heesen M, Neumann K, Hempelmann GG. Influence of different volume therapies and pentoxifylline infusion on circulating soluble adhesion molecules in critically ill patients. Crit Care Med 1996;24:385-91.

24 Boldt J, Mueller M, Menges T, Papsdorf M, Hempelmann G. Influence of different volume therapy regimens on regulators of the circulation in the critically ill. Brit $J$ Anaesth 1996;77:480-7.

25 Boldt J, Müller M, Mentges D, Papsdorf M, Hempelmann G. Volume therapy in the critically ill: is there a difference? Intens Care Med 1998;24:28-36.

26 Boldt J, Suttner S, Huttner I, Kumle B, Piper S, Krumholz W. Are cost of a crystalloid-based volume replacement regimen lower than of a colloid-based volume replacement strategy? Infusionsther Transfusionsmed 2001;28:144-9.

27 Boldt J, Haisch G, Suttner S, Kumle B, Schellhaass A. Effects of a new modified, balanced hydroxyethyl starch preparation (Hextend) on measures of coagulation. Brit $J$ Anaesth 2002;89:722-8.

28 Boldt J, Ducke M, Kumle B, Papsdorf M, Zurmeyer EL. Influence of different volume replacement strategies on inflammation and endothelial activation in the elderly undergoing major abdominal surgery. Intens Care Med 2004;30:416-22.

29 Boldt J, Schölhorn T, Mayer J, Piper S, Suttner S. The value of an albumin-based intravascular volume replacement strategy in elderly patients undergoing major abdominal surgery. Anest Analg 2006;103:191-9.

30 Bulanov Alu, Gorodetskii V, Shulutko EM, Vasil'ev SA, Orel EB, Malofeev VN, et al. Effect of different colloid volume-replacing solutions on a changed hemostasis system. Anesteziologiia i Reanimatologiia 2004;Mar-Apr:25-30.

31 Chen $\mathrm{F}$, Wang $\mathrm{C}$, Wang $\mathrm{Y}$, Lin M, Ke J, Zhang Z. Effect of infusion with different volume expanders on cytokines in choleystitis patients undergoing cholecystectomy. Med $J$ Wuhan University 2006;27:520-2.

32 Franz A, Braeunlich P, Gamsjager T, Felfernig M, Gustorff B, Kozek-Langenecker SA. The effects of hydroxyethyl starches of varying molecular weights on platelet function. Anesth Analg 2001;92:1402-7.

33 Gondos T, Marjanek Z, Ulakcsai Z, Szabo Z, Bogar L, Karolyi M, et al. Short-term effectiveness of different volume replacement therapies in postoperative hypovolaemic patients. Eur J Anaesth 2010;27:794-800.

34 Haas T, Preinreich A, Oswald E, Pajk W, Berger J, Kuehbacher G, et al. Effects of albumin $5 \%$ and artificial colloids on clot formation in small infants. Anaesthesia 2007;62:1000-7.

35 Harten J, Crozier JE, McCreath B, Hay A, McMillan DC, McArdle CS, et al. Effect of intraoperative fluid optimisation on renal function in patients undergoing emergency abdominal surgery: a randomised controlled pilot study (ISRCTN 11799696). Int J Surg 2008;6:197-204.

36 Van der Heijden M, Verheij J, van Nieuw Amerongen GP, Groeneveld AB. Crystalloid or colloid fluid loading and pulmonary permeability, edema, and injury in septic and nonseptic critically ill patients with hypovolemia. Crit Care Med 2009;37:1275-81.

37 Jones SB, Whitten CW, Despotis GJ, Monk TG. The influence of crystalloid and colloid replacement solutions in acute normovolemic hemodilution: a preliminary survey of hemostatic markers. Anesth Analg 2003;96:363-8.

38 Jover JL, García JP, Martínez C, Espí A, Gregori E, Almagro J. [Hydroxyethyl starch to protect renal function in laparoscopic surgery]. Rev Esp Anestesiol Reanim 2009;56:27-30.

39 Kumle B, Boldt J, Piper S, Schmidt C, Suttner S, Salopek S. The influence of different intravascular volume replacement regimens on renal function in the elderly. Anesth Analg 1999;89:1124-30

40 Li F, Sun H, Han XD. The effect of different fluids on early fluid resuscitation in septic shock. Zhongguo Wei Zhong Bing Ji Jin Yi Xue 2008;20:472-5.

41 Mukhtar A, Aboulfetouh F, Obayah G, Salah M, Emam M, Khater Y, et al. The safety of modern hydroxyethyl starch in living donor liver transplantation: a comparison with human albumin. Anest Analg 2009;109:924-30.

42 Pape L, Ahlenstiel T, Ehrich J. Equivalent efficacy of HES 130/0.4 and albumin infusions in children. Pediatr Nephrol 2008;23:1630. 
43 Protsenko DN, Leiderman IN, Grigor'ev EV, Kokarev EA, Levit AL, Gel'fand BR. Evaluation of the effectiveness and safety of synthetic colloid solutions in the treatment of severe abdominal sepsis: a randomized comparative study. Anesteziol Reanim 2009;9-13.

44 Schramko AA, Suojaranta-Ylinen RT, Kuitunen AH, Raivio PM, Kukkonen SI, Niemi TT Comparison of the effect of $6 \%$ hydroxyethyl starch and gelatine on cardiac and stroke volume index: a randomized, controlled trial after cardiac surgery. Perfusion-UK 2010;25:283-91.

$45 \mathrm{Kim} \mathrm{DH}$, Beez M, Kulkarni H. Comparative hemodynamic evaluation of hydroxyethyl starch (HES 130/0.4) and albumin in high-risk surgical patients. Transfus Altern Transfus Med 2005;7:79.

46 Reine PA, Kongsgaard UE, Andersen A, Thøgersen AK, Olsen H. Infusion of albumin attenuates changes in serum protein binding of drugs in surgical patients compared with volume replacement with HAES. Acta Anaesth Scand 2008;52:406-12.

47 Trof RJ, Sukul SP, Twisk JW, Girbes AR, Groeneveld AB. Greater cardiac response of colloid than saline fluid loading in septic and non-septic critically ill patients with clinical hypovolaemia. Intensive Care Med 2010;36:697-701.

48 Veneman TF, Nijhuis JO, Woittiez AJJ. Human albumin and starch administration in critically ill patients: a prospective randomized clinical trial. Wien Klin Wochenschr 2004;116:305-9.

49 Verheij J, van Lingen A, Raijmakers PGHM, Rijnsburger ER, Veerman DP, Wisselink W, et al. Effect of fluid loading with saline or colloids on pulmonary permeability, oedema and lung injury score after cardiac and major vascular surgery. Brit $J$ Anaesth 2006;96:21-30.

50 Du XJ, Hu WM, Xia Q, Huang ZW, Chen GY, Jin XD, et al. Hydroxyethyl starch resuscitation reduces the risk of intra-abdominal hypertension in severe acute pancreatitis. Pancreas 2011;:40:1220-5.

51 Basel Starch Evaluation in Sepsis (BaSES). Last verified August 2011. 2012. http // clinicaltrials.gov/ct2/show/NCT00273728.

52 Palumbo D, Servillo G, D'Amato L, Volpe ML, Capogrosso G, De Robertis E, et al. The effects of hydroxyethyl starch solution in critically ill patients. Minerva Anestesiol 2006;72:655-64.

53 Dolecek M, Svoboda P, Kantorová I, Scheer P, Sas I, Bíbrová J, et al. Therapeutic influence of $20 \%$ albumin versus $6 \%$ hydroxyethylstarch on extravascular lung water in septic patients: a randomized controlled trial. Hepato-gastroenterol 2009;56:1622-8.

54 Dubin A, Pozo MO, Casabella CA, Murias G, Moseinco MC, Kanoore Edul VS, et al. Comparison of $6 \%$ hydroxyethyl starch $130 / 0.4$ and saline solution for resuscitation of the microcirculation during the early goal-directed therapy of septic patients. J Crit Care 2010;25:659.e1-659.e8.

$55 \mathrm{Lv}$ J, Zhao H-Y, Liu F, An Y-Z. The influence of lactate Ringer solution versus hydroxyethy starch on coagulation and fibrinolytic system in patients with septic shock. Zhongguo Wei Zhong Bing Ji Jin Yi Xue 2012;24:38-41.

56 Zhu G-C, Quan Z-Y, Shao Y-S, Zhao J-G, Zhang Y-T. The study of hypertonic saline and hydroxyethyl starch treating severe sepsis. Zhongguo Wei Zhong Bing Ji Jin Yi Xue 2011;23:150-3.
57 ICH Steering Committee. International conference on harmonisation of technical requirements for registration of pharmaceuticals for human use. ICH harmonised tripartite guideline for good clinical practice, 3rd ed. Brookwood Medical Publications; 1998.

58 Bellmann R, Feistritzer C, Wiedermann CJ. Effect of molecular weight and substitution on tissue uptake of hydroxyethyl starch: a meta-analysis of clinical studies. Clin Pharmacokinet 2012;51:225-36.

59 Pillebout E, Nochy D, Hill G, Conti F, Antoine C, Calmus Y, et al. Renal histopathological lesions after orthotopic liver transplantation (OLT). Am J Transplant 2005:5:1120-9.

60 Christidis C, Mal F, Ramos J, Senejoux A, Callard P, Navarro R, et al. Worsening of hepatic dysfunction as a consequence of repeated hydroxyethylstarch infusions. $J$ Hepatol 2001;35:726-32.

61 Schmidt-Hieber M, Loddenkemper C, Schwartz S, Arntz G, Thiel E, Notter M. Hydrops lysosomalis generalisatus - an underestimated side effect of hydroxyethyl starch therapy? Eur J Haematol 2006;77:83-5.

62 Clermont G, Acker CG, Angus DC, Sirio CA, Pinsky MR, Johnson JP. Renal failure in the ICU: comparison of the impact of acute renal failure and end-stage renal disease on ICU outcomes. Kidney Int 2002;62:986-96

63 Bagshaw SM, Uchino S, Bellomo R, Morimatsu H, Morgera S, Schetz M, et al. Septic acute kidney injury in critically ill patients: clinical characteristics and outcomes. Clin J Am Soc Nephrol 2007:2:431-9.

64 Thomas-Rueddel DO, Vlasakov V, Reinhart K, Jaeschke R, Rueddel H, Hutagalung R, et al. Safety of gelatin for volume resuscitation-a systematic review and meta-analysis. Intensive Care Med 2012;38:1134-42.

65 Finfer S, McEvoy S, Bellomo R, McArthur C, Myburgh J, Norton R. Impact of albumin compared to saline on organ function and mortality of patients with severe sepsis. Intensive Care Med 2011:37:86-96.

66 Bellomo R, Ronco C, Kellum JA, Mehta RL, Palevsky P, and the ADQI workgroup. Acute renal failure-definition, outcome measures, animal models, fluid therapy and information technology needs: the Second International Consensus Conference of the Acute Dialysis Quality Initiative (ADQI) Group. Crit Care 2004;8:R204-12.

67 Mehta RL, Kellum JA, Shah SV, Molitoris BA, Ronco C, Warnock DG, et al. Acute Kidney Injury Network: report of an initiative to improve outcomes in acute kidney injury. Crit Care 2007:11:R31.

\section{Accepted: 30 January 2013}

\section{Cite this as: BMJ 2013;346:f839}

This is an open-access article distributed under the terms of the Creative Commons Attribution Non-commercial License, which permits use, distribution, and reproduction in any medium, provided the original work is properly cited, the use is non commercial and is otherwise in compliance with the license. See: http://creativecommons.org/licenses/bync/2.0/ and http://creativecommons.org/licenses/by-nc/2.0/legalcode. 


\section{Tables}

\begin{tabular}{|c|c|c|c|c|c|c|c|c|c|c|c|}
\hline Trial & $\begin{array}{c}\text { No of } \\
\text { patients }\end{array}$ & $\begin{array}{l}\text { Centre } \\
\text { status, } \\
\text { setting }\end{array}$ & Blinding & $\begin{array}{c}\text { No of } \\
\text { intervention } \\
\text { groups }\end{array}$ & $\begin{array}{l}\text { Diagnostic } \\
\text { group }\end{array}$ & $\begin{array}{l}\text { Indication } \\
\text { for } \\
\text { intervention }\end{array}$ & $\begin{array}{l}\text { HES } \\
\text { solution }\end{array}$ & Comparator & $\begin{array}{l}\text { Intervention } \\
\text { period }\end{array}$ & $\begin{array}{c}\text { Total dose of } \\
\text { HES }\end{array}$ & $\begin{array}{l}\text { Contact } \\
\text { with } \\
\text { authors } \\
\text { successful }\end{array}$ \\
\hline $6 S^{9}$ & 804 & $\begin{array}{l}\text { Multicentre, } \\
\text { ICU }\end{array}$ & Yes & 2 & Severe sepsis & Resuscitation & $\begin{array}{l}6 \% \\
\text { Tetraspan* }\end{array}$ & $\begin{array}{l}\text { Ringer's } \\
\text { acetate }\end{array}$ & $\begin{array}{l}\text { ICU stay. } \\
\text { Maximum } 90 \\
\text { days }\end{array}$ & $\begin{array}{l}\text { Median } 3000 \\
\text { (IQR 1507-5100) }\end{array}$ & Yes \\
\hline BaSES $^{51}$ & 241 & $\begin{array}{l}\text { Two ICUs } \\
\text { in one } \\
\text { hospital }\end{array}$ & Yes & 2 & Sepsis & Resuscitation & $\begin{array}{l}6 \% \\
\text { Voluvent }\end{array}$ & $\begin{array}{l}\text { Isotonic } \\
\text { saline }\end{array}$ & 5 days & $\begin{array}{l}\text { Median } 3775 \\
\text { (IQR 2018-6347) }\end{array}$ & Yes \\
\hline $\mathrm{CHEST}^{10}$ & 1937 & $\begin{array}{l}\text { Multicentre, } \\
\text { ICU }\end{array}$ & Yes & 2 & Sepsis & Resuscitation & $\begin{array}{l}6 \% \\
\text { Voluvent }\end{array}$ & $\begin{array}{l}\text { Isotonic } \\
\text { saline }\end{array}$ & $\begin{array}{l}\text { ICU stay. } \\
\text { Maximum } 90 \\
\text { days }\end{array}$ & $\begin{array}{l}\text { Mean } 2104 \text { (SD } \\
850 \ddagger)\end{array}$ & Yes \\
\hline CRYSTMAS ${ }^{11}$ & 196 & $\begin{array}{l}\text { Multicentre, } \\
\text { ICU }\end{array}$ & Yes & 2 & Severe sepsis & Resuscitation & $\begin{array}{l}6 \% \\
\text { Voluvent }\end{array}$ & $\begin{array}{l}\text { Isotonic } \\
\text { saline }\end{array}$ & 4 days & $\begin{array}{l}\text { Mean } 2615 \text { (SD } \\
\text { 1499) }\end{array}$ & Yes \\
\hline $\begin{array}{l}\text { Dolecek } \\
2009^{53}\end{array}$ & 56 & Single, ICU & No & 2 & Severe sepsis & Fixed dose & $\begin{array}{l}6 \% \\
\text { Voluvent }\end{array}$ & Albumin $20 \%$ & 3 days & $\begin{array}{l}4 \times 250 \mathrm{~mL} / \text { day in } \\
3 \text { days }\end{array}$ & Yes \\
\hline Dubin $2010^{54}$ & 25 & $\begin{array}{l}\text { Multicentre, } \\
\text { ICU }\end{array}$ & No & 2 & $\begin{array}{l}\text { Sepsis and } \\
\text { tissue } \\
\text { hypoperfusion }\end{array}$ & Resuscitation & $\begin{array}{l}6 \% \\
\text { Voluvent }\end{array}$ & $\begin{array}{l}\text { Isotonic } \\
\text { saline }\end{array}$ & 24 hours & $\begin{array}{l}\text { Mean } 2610 \text { (SD } \\
\text { 885) }\end{array}$ & Yes \\
\hline Lv $2012^{55}$ & 42 & Single, ICU & Unclear & 2 & Septic shock & Resuscitation & Unclear & $\begin{array}{l}\text { Ringer's } \\
\text { lactate }\end{array}$ & 24 hours & $\begin{array}{l}\text { Mean } 2770(\text { SD } \\
590)\end{array}$ & No \\
\hline $\begin{array}{l}\text { Palumbo } \\
2006^{52}\end{array}$ & 20 & Single, ICU & No & 2 & Severe sepsis & $\begin{array}{l}\text { Maintenance } \\
\text { of pulmonary } \\
\text { capillary } \\
\text { wedge } \\
\text { pressure }\end{array}$ & $\begin{array}{l}6 \% \\
\text { Voluvent }\end{array}$ & Albumin $20 \%$ & Unclear & $\begin{array}{l}\text { No information } \\
\text { on doses }\end{array}$ & No \\
\hline Zhu $2011^{56}$ & 135 & Single, ICU & No & 3 & Severe sepsis & Resuscitation & $\begin{array}{l}6 \% \text { HES } \\
130 / 0.4 \\
\text { (unclear } \\
\text { brand) }\end{array}$ & $\begin{array}{l}\text { Ringer's } \\
\text { lactate }\end{array}$ & 24 hours & $\begin{array}{l}\text { HES+hypertonic } \\
\text { saline group: } \\
\text { mean } 5475 \text { (SD } \\
209), \text { HES } \\
\text { group: mean } \\
6383 \text { (SD 287) }\end{array}$ & No \\
\hline
\end{tabular}

$\mathrm{HES}=$ hydroxyethyl starch; ICU=intensive care unit; IQR=interquartile range; $\mathrm{SD}=$ standard deviation. ${ }^{*} 6 \%$ hydroxyethyl starch 130/0.42 in Ringer's acetate (B Braun Melsungen, Melsungen, Germany). †\% hydroxyethyl starch 130/0.4 in saline (Fresenius Kabi, Bad Homburg, Germany).

‡Only reported for first four days. 
Table 2| Observation period for outcomes

\begin{tabular}{|c|c|c|c|c|c|c|}
\hline Trial & Mortality & Renal replacement therapy & Acute kidney injury & $\begin{array}{l}\text { Red blood cell } \\
\text { transfusion }\end{array}$ & Bleeding and blood loss & Serious adverse events \\
\hline $6 S^{9}$ & 90 days & 90 days & ICU & ICU & $\mathrm{ICU}$ & ICU \\
\hline BaSES $^{51}$ & 1 year & 1 year & - & - & - & - \\
\hline $\mathrm{CHEST}^{10}$ & 90 days & - & - & - & - & - \\
\hline CRYSTMAS $^{11}$ & 90 days & ICU & $\mathrm{ICU}$ & $\mathrm{ICU}$ & $4 / 8$ days & ICU \\
\hline Dolecek $2009^{53}$ & 28 days & 72 hours & 72 hours & - & - & 72 hours \\
\hline Dubin $2010^{54}$ & 28 days & 24 hours & 24 hours & 24 hours & 一 & 24 hours \\
\hline Lv $2012^{55}$ & Unclear* $^{*}$ & - & - & - & - & - \\
\hline Palumbo $2006^{52}$ & - & - & - & 一 & - & - \\
\hline Zhu $2011^{56}$ & 24 hours & - & - & - & - & - \\
\hline
\end{tabular}

$\mathrm{ICU}=$ intensive care unit.

*Death in hospital or ICU, although not specifically stated. 
Table 3| Risk of bias

\begin{tabular}{|c|c|c|c|c|c|c|c|c|}
\hline Trial & $\begin{array}{c}\text { Random sequence } \\
\text { generation }\end{array}$ & $\begin{array}{l}\text { Allocation } \\
\text { concealment }\end{array}$ & Blinding & $\begin{array}{l}\text { Incomplete } \\
\text { outcome data }\end{array}$ & $\begin{array}{l}\text { Selective } \\
\text { outcome } \\
\text { reporting }\end{array}$ & $\begin{array}{l}\text { Baseline } \\
\text { imbalance }\end{array}$ & $\begin{array}{l}\text { Vested financial } \\
\text { interests }\end{array}$ & Academic bias \\
\hline $6 S^{9}$ & Low & Low & Low & Low & Low & Low & Low & Low \\
\hline BaSES $^{51}$ & Low & Low & Low & Low & Low & Low & Low & Low \\
\hline $\mathrm{CHEST}^{10}$ & Low & Low & Low & Low & Low & Low & Low & Low \\
\hline CRYSTMAS ${ }^{11}$ & Low & Low & Low & Low & Low & Low & High & High \\
\hline Dolecek $2009^{53}$ & Low & Low & Low & Low & Low & Low & Low & Low \\
\hline Dubin $2010^{54}$ & Low & Low & High & Low & Low & Low & Low & Low \\
\hline Lv $2012^{55}$ & Low & High & Unclear & Unclear & Low & Low & Unclear & Unclear \\
\hline Palumbo $2006^{52}$ & Unclear & High & Unclear & Low & High & Low & Unclear & Low \\
\hline Zhu $2011^{56}$ & Unclear & High & High & Unclear & Low & Low & Low & Unclear \\
\hline
\end{tabular}

See supplementary file to support judgment. 


\section{Figures}

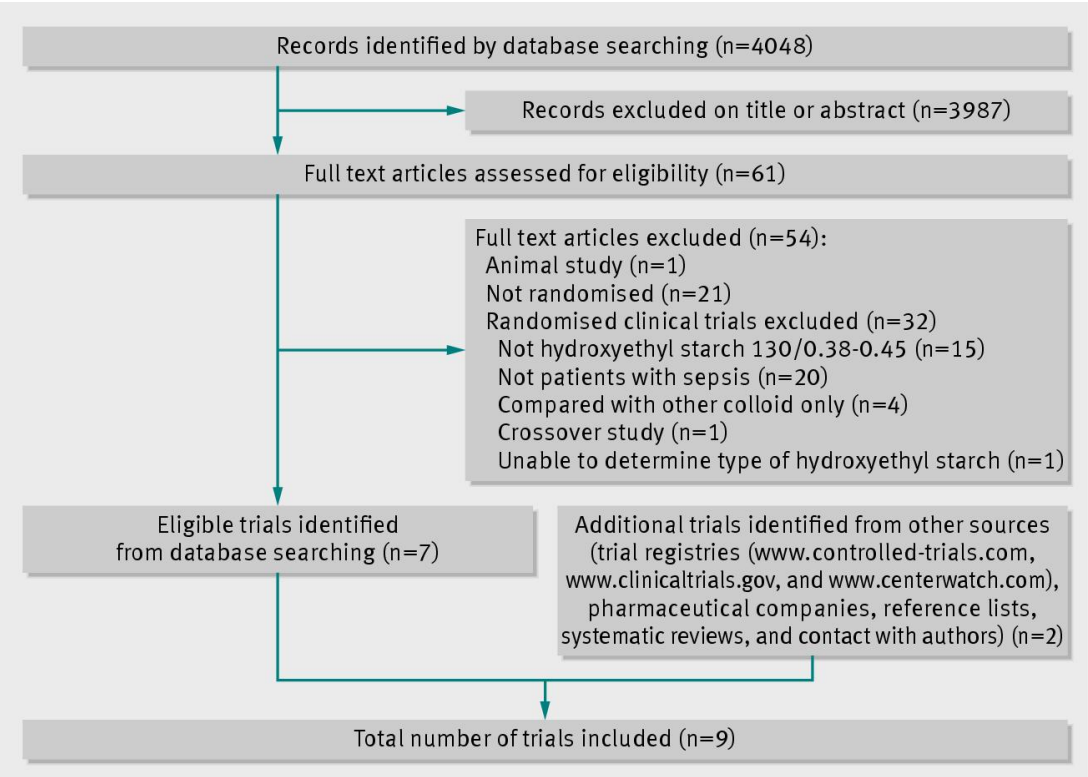

Fig 1 Flow of papers through review. Each of the 32 excluded randomised clinical trials may have more than one reason for exclusion

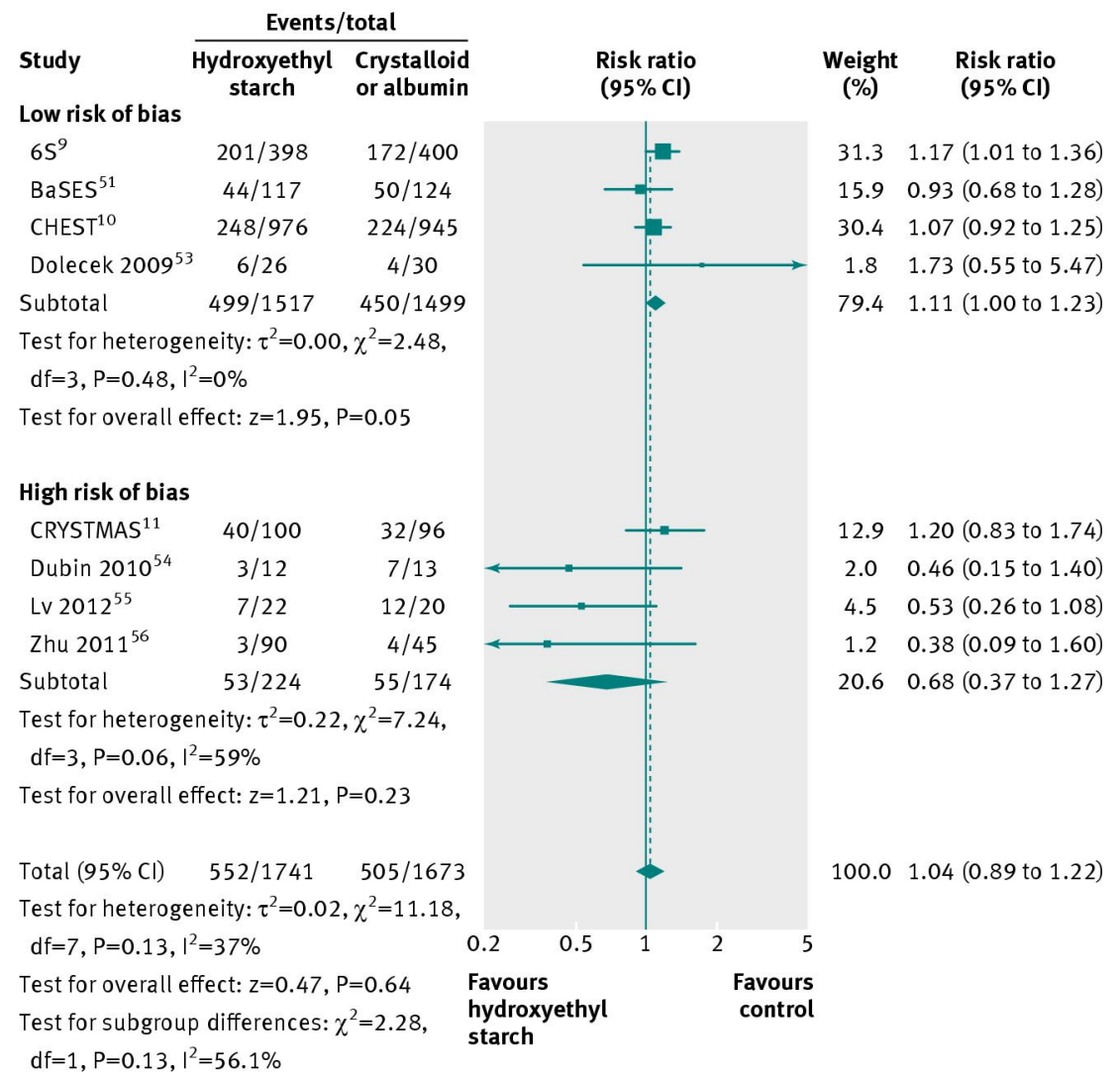

$\mathrm{df}=1, \mathrm{P}=0.13, \mathrm{I}^{2}=56.1 \%$

Fig 2 Forest plot of all cause mortality in relation to risk of bias in trials. Size of squares for risk ratio reflects weight of trial in pooled analyses. Horizontal bars represent $95 \%$ confidence intervals 


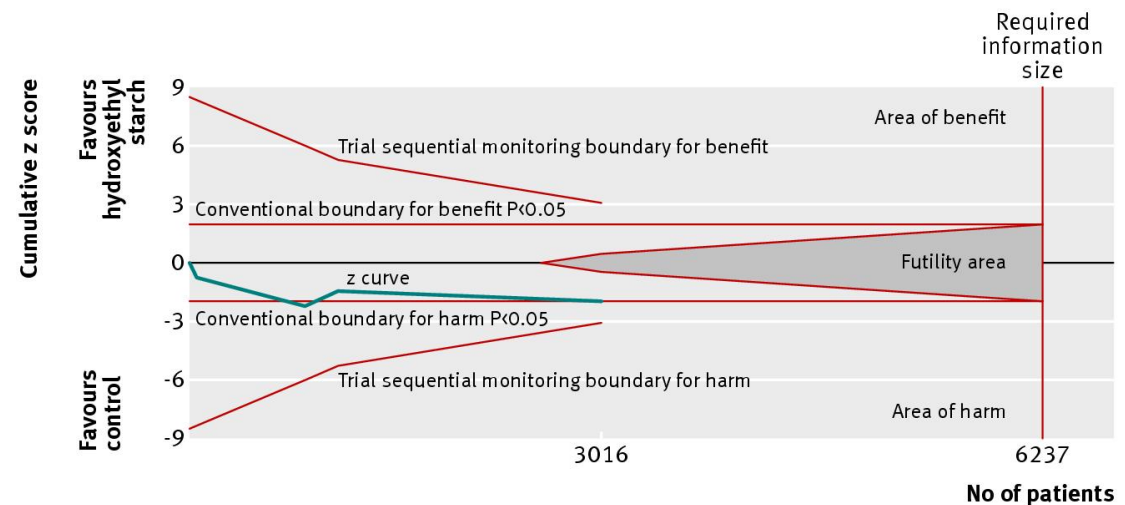

Fig 3 Trial sequential analysis of mortality in four trials with low risk of bias. A diversity adjusted information size of 6237 patients was calculated using $\alpha=0.05$ (two sided), $\beta=0.20$ (power $80 \%$ ), $D^{2}=0 \%$, an anticipated relative risk increase of $11 \%$, and an event proportion of $30 \%$ in the control arm. The blue cumulative $z$ curve was constructed using a random effects model

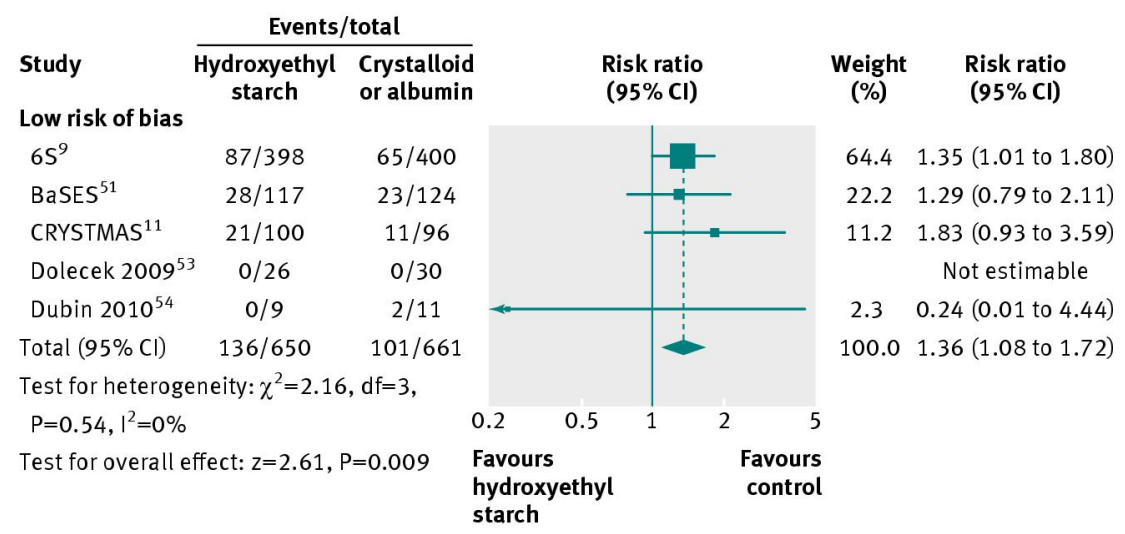

Fig 4 Forest plot of renal replacement therapy. Size of squares for risk ratio reflects weight of trial in pooled analyses. Horizontal bars represent $95 \%$ confidence intervals

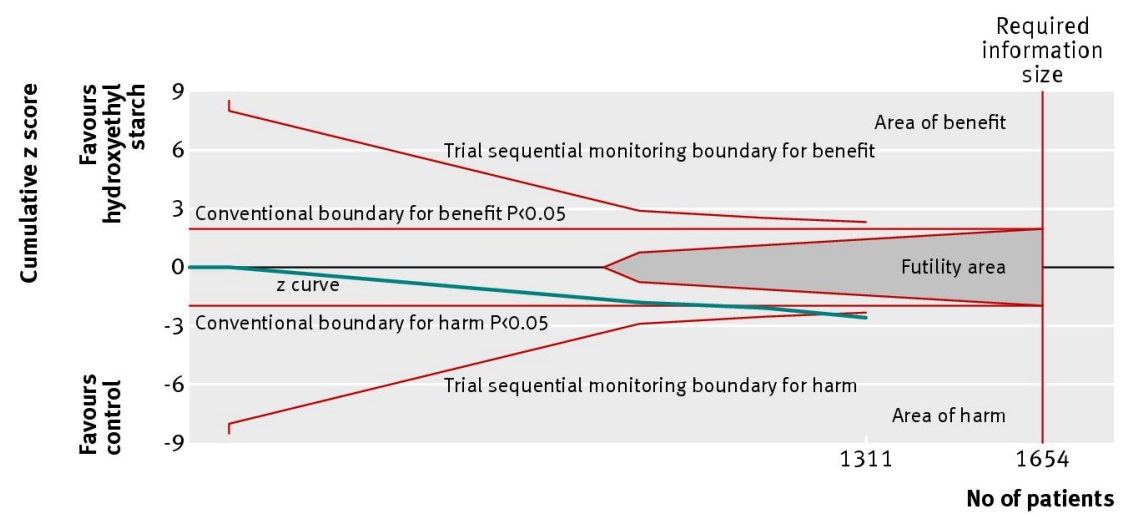

Fig 5 Trial sequential analysis of renal replacement therapy. A diversity adjusted information size of 1654 patients was calculated using $\alpha=0.05$ (two sided), $\beta=0.20$ (power $80 \%$ ), $D^{2}=0 \%$, an anticipated relative risk increase of $35 \%$ and an event proportion of $15 \%$ in the control arm. The blue cumulative $z$ curve was constructed using a fixed effects model. Trials with no events were included in the analysis with an empirical continuity correction of 0.01 